\title{
The Effect of Overcompensation Information Frame on Brand Trust: The Interactive Ritual Chains Perspective
}

\author{
Wei Wei, Haiying Wei, Yaxuan Ran, Hongyan Liu \\ School of Management, Jinan University, Guangzhou, China \\ Email:vanywei@163.com, tweihy@126.com,ranyxuan@163.com,hongyanliu2015@163.com
}

How to cite this paper: Wei, W., Wei, H.Y., Ran, Y.X. and Liu, H.Y. (2017) The Effect of Overcompensation Information Frame on Brand Trust: The Interactive Ritual Chains Perspective. Journal of Service Science and Management, 10, 13-27. https://doi.org/10.4236/jssm.2017.101002

Received: January 23, 2017

Accepted: February 21, 2017

Published: February 24, 2017

Copyright ( 92017 by authors and Scientific Research Publishing Inc. This work is licensed under the Creative Commons Attribution International License (CC BY 4.0). http://creativecommons.org/licenses/by/4.0/

\begin{abstract}
Companies will provide overcompensation for some reasons in brand crisis, which means that companies have to consider how to frame the information of overcompensation. Is punishing offenders or compensate victims better? Based on the Interactive Ritual Chain Theory, this research debates the effect of overcompensation information frame on brand trust. We conduct experiment and find that, in performance-related crisis, the overcompensation framed in compensating victims will increase more brand trust than punishing offenders, and perceived benevolence mediates the effect; in value-related crisis, the overcompensation framed in punishing offenders will increase more brand trust than compensating victims, and perceived integrity mediates the effect. Implications and future research directions are discussed.
\end{abstract}

\section{Keywords}

Overcompensation, Brand Crisis, Interactive Ritual Chain Theory

\section{Introduction}

Compensation is an appropriate way to resolve conflicts when the companies' misconducts violate the benefit of consumer [1]. As a very important form of compensation, overcompensation, which means offenders provide extra compensation than the loss of victims, is wildly recognized and used by management practice [2]. For instance, in the accident of benzene exceeding the standard induced by Jinhao Camellia Oil Company in 2010, Jinhao Camellia Oil Company paid extra money to consumers which were ten times than the number needed to reach the loss. Samsung provided extra one-year warranty when compensated the victims for its eMMC defects in 2013. The outcomes of overcompensation 
are different. Some brands rebuilt the trust of consumer, such as Samsung, Dianping, while others made things worse, such as Jinhaochayou. What makes different? Researches to date have not given answers to this question, which focus on comparing the effect of overcompensation and equal compensation [3] [4].

Overcompensation transmits two meanings. One is compensating victims, which delivers goodwill and sincerity by making up the loss of victims, another is punishing offenders, which delivers the faith to conform with social norms by giving up the interests voluntarily [5] [6]. There are differences in two meanings of overcompensation. Firstly, the former pays attention to victims, while the latter focuses on offenders. Secondly, compensation is a way to give, while punishment is a way to lose. There are so many researches talking about the different between compensation and punishment, while the question of how to use the information frame of overcompensation effectively has not been solved yet.

This paper is talking about this question and to find the factor that determines the effect of information frame of overcompensation. In Interaction Ritual Chains Theory, interaction has situational continuous effect like chains, which means that the effect of current interaction is influenced by last interaction. Taking interaction ritual theory into brand crisis restoration, brand crisis types, represent the last interaction between brand and consumer, have influence on the next interaction, such as overcompensation. Two types of brand crisis are talked about in brand crisis field. One is performance-related crisis, which is about product and affects consumers' perception of functional value of brand, another is value-related crisis, such as product harm crisis, which is about social or ethic problems and affects the perception of symbolic and emotional value of brand, such as social responsibility crisis [7]. Based on interaction ritual chain theory, we demonstrate that, in performance-related crisis, consumer is focus on the benefit of victims, and has more trust when brand provides overcompensation framed as compensating victims and perceived benevolence mediates the effect; in value-related crisis, consumer is focus on the conducts of brand, and has more trust when brand provides overcompensation framed as punishing offenders and perceived integrity mediates the effect.

\section{Hypothesis}

\subsection{Overcompensation and Information Frame}

Based on the financial amount, compensation can be divided into three types, under compensation, equal compensation, and overcompensation. Overcompensation is compensation that is great than the damage victims suffered [2] [5] [8]. The existing researches have demonstrated that overcompensation is better than equal compensation and under compensation based on different theories, such as Discrimination Expectation Theory, Resource Exchange Theory, Prospect Theory, which can increase the satisfaction of consumer, change victims' negative evaluation, and improve the opportunity of next interaction between victims and offenders [3] [9] [10] [11] [12]. 
In the past studies, scholars mainly focus on discussing the results and consequences of overcompensation, but ignore the influencing factors of overcompensation. As a key factor through which companies transfer the compensation information to consumers, the overcompensation information frame can determine people's cognitive processing of overcompensation [13] [14]. According to opinions held by scholars [15], the information regarding companies' overcompensation for customers can be framed the punishments upon the violators. For example, the company of Jinhao Camellia Oil thinks that the 10 times compensation provided to consumers was due to its own mistakes. The information can also be framed the compensations provided to the victims. For example, Samsung believes that the extra after-service provided to consumers is because of guaranteeing the benefits of consumers. Now, no coherent conclusions have been made as to which information framework is more effective. Some studies suggest that the compensation framework can not only express the guilt of violators, but also transmit violators' wishes to maintain the social standards. Therefore, people generally prefer to punish the violators [16] [17] [18]. However, other studies demonstrate that the compensation framework shall make violators feel warmer, reduce the distance between people and the violators and result in better repair effect [19].

\subsection{Interactive Ritual Chains and Mutual Focus of Attention}

The repair of brand crisis is the interactive process between brand and consumers. The results of crisis repair depend on the quality of interaction between brand and consumers [20]. The theory of Interactive Ritual Chains [21] argues that the successful interaction relies on the focus matching between both parties of interactive process, namely the Mutual Focus of Attention. The mutual focus of attention means that both parties in the interactive process not only know what they should focus on, but also are conscious of the fact that the contents paid attention to by the other party are consistent with their own. Based on which, the behavioral expectations upon the other party are formed. If these expectations are confirmed, the rhythmed interaction shall be formed. This interactive rhythmicity is key to the formation of emotional connections between both parties and group identification. In the short time, the mutual focus of attention shall help the both parties of interactive process to form the wills for another time of interaction. In the long run, the mutual focus of attention can develop the shared emotions of both parties of interactive process, and form the beneficial long-term trust and stable relationship. Studies show that in the interactive context of conflict resolving, the matching of focus of attention is considered as the key factor to the relationship repair [22]. Based on this, the successful repair of brand crisis needs the companies and consumers to build the mutual focus of attention. Companies are required to base on the relevant information to conclude consumers' focus of attention. According to which, the corresponding measures shall be appropriately chosen to guarantee the consistent focus of attention between both parties in the interactive process. 


\subsection{Information Framework for Violator Punishment and Value-Related Crisis}

Most of value-related crises are involved with the social and moral issues of companies rather than the consumers. There's a relatively long psychological distance between this critical incident and the target consumers of the brand. The existing studies show that with the relatively long psychological distance, individuals shall represent the critical incident in a more abstract sense, consider the critical incident as the violation of public values and social standards, additionally pay much attention to the misconducts of companies. Consumers' focus of attention is upon the companies [16]. Therefore, in the process of repairing the crisis in values, companies should also be deeply concerned with their own conducts and actions and show their respects to the social standards. Punishment is an important mean for the maintenance of group identification. Individuals with high level of group identification is more inclined to keep the group's standards of behaviors [23] and to punish those actions violating the group unity and the identification of group's members [24]. Framing the punishment for overcompensation, shows that companies have known their violating of group's standards of behavior and are willing to keep the identification granted to the group. Further, since the group identification is an important part of self-identification [25], companies' focus of attention is upon the companies. It's concluded in this study that when a crisis occurs to the values, consumers shall express great concern over the companies. Framing the punishment for overcompensation demonstrates that companies' focus of attention lies in themselves and the mutual focus of attention has been built between companies and consumers Thus, it's assumed that:

H1 a: In value-related brand crisis, compared with compensation framework, the overcompensation of punishment framework shall be more effective in repairing brand trust.

Mayer, et al. (1995) studied and found that characteristics predicting the trust included capability, integrity and benevolence. Integrity means the consistence between the actions and words of individuals, and is the standard-related virtues [26]. When the individual's actions are found to be consistent with social behavioral standards, this individual is thought to be an honest one. The punishment framework of overcompensation means that companies volunteer to punish their own actions which violate the social standards, which shows their willing to more strictly respect the social norms in the future. Thus, consumers' perceived integrity upon the companies shall be improved [18]. Therefore, we assume that:

$H 1$ b: In value-related brand crisis, perceived integrity is the mediator that the overcompensation information frame of companies influence brand trust.

\subsection{Victim-Compensating Information Frame and Performance-Related Crisis}

The performance-related crisis is mainly involved with the quality of product 
and consumers are the direct victim of any crisis. The psychological distance between this critical incident and the brand's consumers is relatively short. Studies demonstrate that with the close psychological distance, individual shall represent this critical incident in a more figurative sense, and shall give weight to the damages brought by this critical incident. Consumers' focus of attention lays on themselves [27] [28]. As a result, in the performance-related brand crisis, companies should focus on the damages suffered by the consumers and give importance to the compensation for these damages.

Compensation is an important mean for making up the damages suffered by the victims. The theory of resource exchange argues that the nature of social interaction is the equal exchange of money, goods, service, care and status [29]. Framing the compensation for the overcompensation demonstrates that companies clearly understand the material damages brought to consumers by the crisis, but also other non-material damages, such as status, time and spirit. Thus, companies are willing to compensate the non-material damages and show their respect towards the interests of victims. Companies consciously maintain the consideration principles and their focus of attention lies in the victims. This study infers that in the context of performance-related crisis, the consumers' focus of attention is on themselves. Additionally, the compensation framework of overcompensation shows that companies' focus of attention is also on the victims and the mutual focus of attention has been built between companies and consumers. Thus, it's assumed that:

H2a: In performance-related crisis, compared with punishment frame, the overcompensation of compensation frame is more effective in repairing brand trust.

Benevolence reflects the good wills of individual upon others, and is a virtue related with others. When individual volunteers to bear the costs by himself and help the victims, this individual is generally considered to be benevolent [30]. The compensation frame of overcompensation means that individual cares more about the interests of victims, and is willing to bear high costs to compensate the damages of victims so as to induce higher-level benevolent perceptions. Therefore, it's assumed that:

H2 b: In performance-related crisis, perceived benevolence is the mediator that companies overcompensation information framework influences the results of repairing crisis.

Based on the hypotheses, the research model is shown in Figure 1. The effect

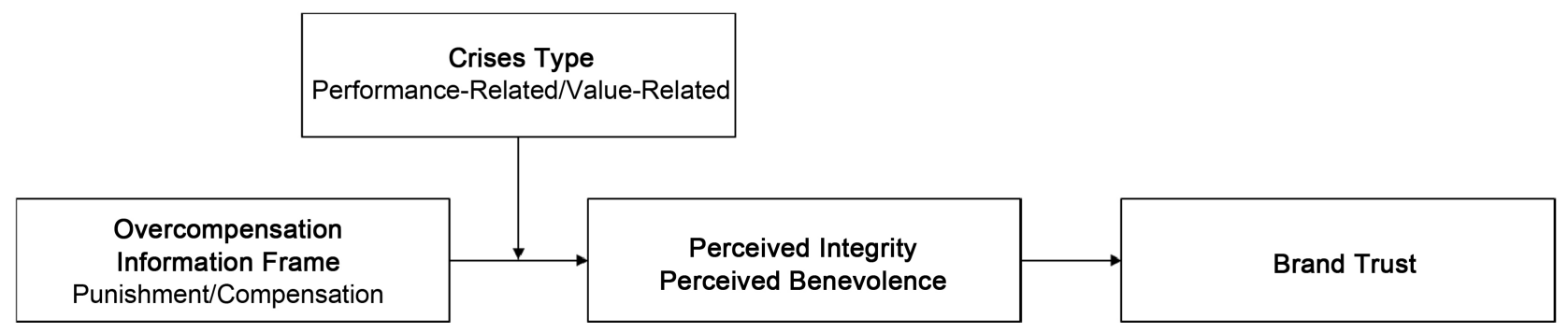

Figure 1. Research model. 
of overcompensation information frame on brand trust is moderated by crises type. In performance-related crisis, consumer is focus on the benefit of victims, and has more trust when brand provides overcompensation framed as compensating victims and perceived benevolence mediates the effect; in value-related crisis, consumer is focus on the conducts of brand, and has more trust when brand provides overcompensation framed as punishing offenders and perceived integrity mediates the effect.

\section{Method}

To prove our hypotheses, we conduct an experiment, that takes participants in fictitious crisis situations and asks them to evaluate their attitude. Before the experiment, we take pilot study to test the manipulation metials.

\subsection{Pilot Study}

Pilot study aims at 1) determining the appropriate crisis-inducing materials; 2) guaranteeing the effective manipulation of overcompensation information frame. To avoid the influences of brand knowledge and brand attachment, the virtual brand Epxtion was utilized in the experiment.

19 undergraduates participated in the pilot study with their average age being 22.5, including 9 males and 10 females. The pilot study is composed of two parts, namely the evaluation of crisis situation and evaluation of overcompensation information. Firstly, to fully consider the incidence and influences of crisis incidents in the clothing industry, we chose four crisis-inducing materials (i.e. overdose of plasticizer in the clothes, sweat shop, under-standardized color fastness and illegal pollution discharge). The participators read the materials about the crisis incident and evaluated the perceptive trueness of the crisis, the perceptive severity and kind of crisis (7-Point Likert Scale. 1 point means "strongly disagree". 4points means "don't know" and 7 points means "strongly agree"). Then, the participators read two pieces of new reports regarding the enterprise's overcompensation (punishment frame and compensation frame) and were required to judge the why the enterprise employed the means of overcompensation.

To control the influences of crisis' severity and the materials' perceptive trueness upon the results of main experiment, we eventually determined "under-standardized color fastness" to be the experimental material for the performance-related crisis and "illegal pollution discharge" for the value-related crisis. All of the participators obviously judged the natures of these two pieces of crisis materials M Performance $=5.79, \mathrm{t}(18)=5.16, \mathrm{p}<0.001, \mathrm{~d}=1.18 ; \mathrm{M}$ Value $=$ $5.95, \mathrm{t}(18)=7.21, \mathrm{p}<0.001, \mathrm{~d}=1.66)$. Besides, the perceptive trueness $\left(\mathrm{M}_{\text {Performance }}=\right.$ $\left.4.95, \mathrm{SD}=1.27, \mathrm{M}_{\text {Value }}=5.08, \mathrm{SD}=0.80, \mathrm{t}(18)=-0.664, \mathrm{p}=0.515, \mathrm{~d}=0.13\right)$ and perceptive severity $\left(\mathrm{M}_{\text {Performance }}=5.37, \mathrm{SD}=1.2, \mathrm{M}_{\text {Value }}=5.74, \mathrm{SD}=1.3, \mathrm{t}(18)=\right.$ $-1.326, p=0.202, d=0.30$ ) of these two pieces of materials didn't differ apparently. For the overcompensation information, most of participators were able to correctly judge the types of its information frame $\left(\mathrm{N}_{\text {Punishment }}=19, \mathrm{p}<0.01, \varphi=\right.$ 
$\left.0.58 ; \mathrm{N}_{\text {Compensation }}=17, \mathrm{p}<0.01, \varphi=0.43\right)$.

\subsection{Main Experiment}

The 2 (type of crisis: performance-related VS. value-related) $\times 2$ (overcompensation information frame: punishment frame VS. compensation frame) design was employed in this experiment. Totally 147 undergraduates took part in this experiment. With incomplete and obviously careless questionnaire of 15 pieces removed, 132 pieces of questionnaire were recovered and the efficiency rate was $89.8 \%$. There were 61 males and 71 females (53.79\%), with their average age being 21.6.

The experiment was conducted in the following order. Firstly, the participators were required to read a piece of news report about the crisis incident of clothing brand, Epxton, and then to evaluate the type of crisis and brand trust (pretesting). Then, participators read a piece of news reports regarding corporate responses towards the crisis, and the participators were tested for the manipulation of overcompensation information frame. Their perceived integrity, perceived benevolence and brand trust were measured (post-testing). Eventually, participators reported the demographic information, including the sex, educational background and age.

The 7-Point Likert Scale was employed in the measurement of this study. Therein, 1 means "strongly disagree", 4 means "don't know" and 7 means "strongly agree". Furthermore, the measurement of brand trust learned from the studies of Xie and Peng (2009) [31]. This scale includes two sub-scales, including the trusting beliefs and trusting intentions. Trusting beliefs have 3 items needing to be measured (such as, I trust this company), so do the trusting intentions (such as, When I need an electronic product, I shall purchase it from this company). In this study, the brand trust after the repair of crisis (post-testing) (Cronbach's $\alpha=0.93$ ) minus the brand trust after the occurrence of crisis (pre-testing) (Cronbach's $\alpha=0.92$ ) is the variable of brand trust, being the indicator measuring the results of repairing the brand crisis. The measurements of perceived integrity and perceived benevolence mainly learned from the scales of Kim et al. (2004) [32] and Xie et al. (2009). Perceived integrity includes four items to be measured (such as, judging from the CEO's explanation, I believe that the responses of Epxton are correct and true; Cronbach's $\alpha=0.89$ ); while the perceived benevolence includes five items (such as , judging from the CEO's explanation, I believe that Epxton shows a great deal of benevolence towards the victims; Cronbach's $\alpha=0.89$ ).

\section{Results}

\subsection{Manipulation Test}

The results of chi-square test suggest that in 122 of 132 questionnaires, the type of crisis was correctly judged, and the manipulation of types of brand crisis was successful $\left(\chi^{2}=95.055, \mathrm{p}<0.000 ; \varphi=0.849\right)$. In a similar way, in 122 of 132 questionnaires, the judgement regarding the overcompensation information 
frame was correct and the manipulation of overcompensation information frame was successful $\left(\chi^{2}=96.447, \mathrm{p}<0.000 ; \varphi=0.855\right)$.

\subsection{Hypothesis Test}

Firstly, the brand trust after the repairing of crisis and after the occurrence of crisis went through the paired samples t-test. The results show that the brand trust after the crisis repair $\left(\mathrm{M}_{\text {after repair }}=3.60\right)$ is significantly higher than that after the occurrence of crisis $\left(\mathrm{M}_{\text {after occurrence }}=2.84\right), \mathrm{t}(131)=-9.413, \mathrm{p}=0.000<0.05$, $\mathrm{d}=0.75$, which means that the overcompensation can effectively improve consumers' trust upon a brand. Considering increment of brand trust as the dependent variable, the result of double factor variance shows that the interaction between type of crisis and overcompensation information frame is significant $\left(\mathrm{F}(1,128)=13.18, \mathrm{p}<0.05, \eta^{2}=0.093\right.$. However, the main effects of crisis type $(\mathrm{F}(1,128)=1.338, \mathrm{p}=0.250)$ and the information frame $(\mathrm{F}(1,128)=0.069, \mathrm{p}=$ 0.794 ) aren't significant. Furthermore, simple effect analysis shows that for the value-related brand crisis, increment of brand trust brought by the overcompensation of compensation frame $(M=0.60)$ is obviously lower than that by the overcompensation of punishment frame $(\mathrm{M}=1.12) \mathrm{F}(1,128)=5.507, \mathrm{p}=0.020<$ $0.05, \eta^{2}=0.041$; thus the hypothesis $\mathrm{H} 1 \mathrm{a}$ is verified. However, in performancerelated brand crisis, increment of brand trust induced by the overcompensation of compensation frame $(\mathrm{M}=0.98)$ is apparently higher than that of overcompensation of punishment frame $(\mathrm{M}=0.38), \mathrm{F}(1,128)=7.812, \mathrm{p}=0.006<0.01$, $\eta^{2}=0.058$. As shown in Figure 2, the hypothesis $\mathrm{H} 2 \mathrm{a}$ is verified.

According to the analysis procedures for mediation effect proposed by Zhao et al. (2010) [33] and the Bootstrap method presented by Preacher et al. (2004) [34] and Hayes (2013) [35], the mediation effect was tested (Model 8, Bootstrapping of 5000 times, confidence interval 95\%). Firstly, the mediation effect of perceived integrity was tested. The results of mediation test excluded 0 (LLCI $=-0.3804$, $\mathrm{ULCI}=-0.0066)$, suggesting that the perceived integrity had significant mediation

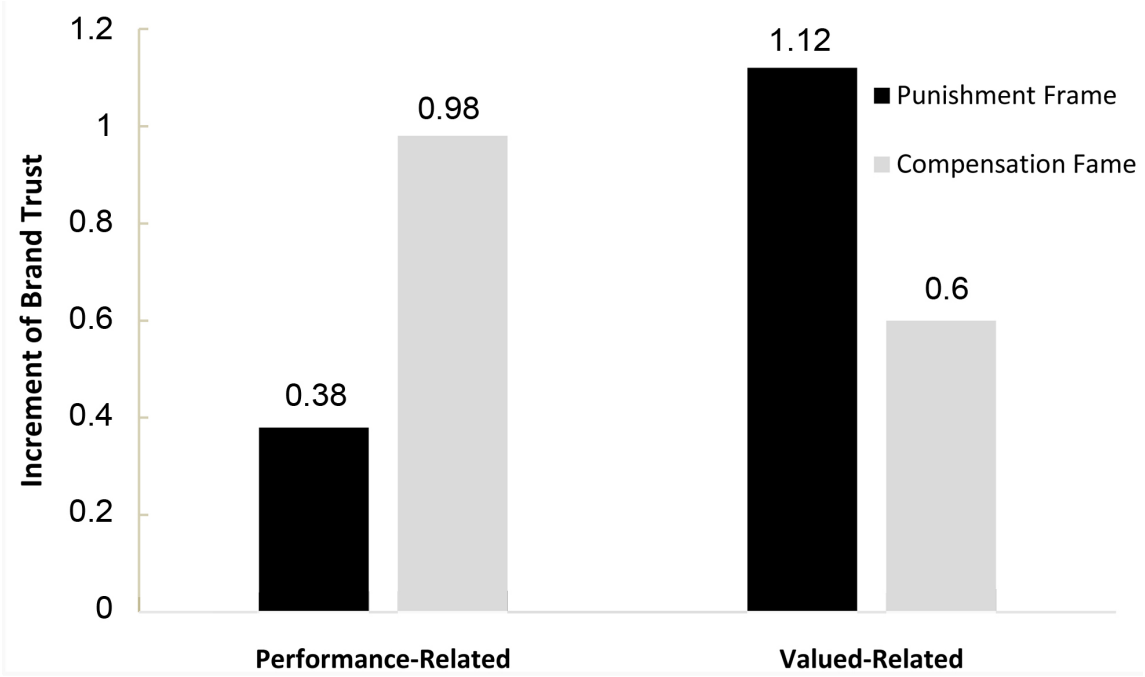

Figure 2. The effect of overcompensation information frame on brand trust. 
effects and the value of mediation effect was -0.1306 . Besides, after having controlled the mediating variable (i.e. the perceived integrity), the interaction of overcompensation information frame and the crisis type still significantly influenced increment of brand trust. The interval excluded 0 (LLCI $=-1.6063, \mathrm{ULCI}=$ $-0.3856)$, suggesting that the perceived integrity was partial mediation. Further analysis showed that in the context of performance-related crisis, the mediation effect of perceived integrity wasn't significant, and the interval included o (LLCI $=$ -0.0788 , ULCI $=0.1425$ ); however, with the value-related crisis, the mediation effect of perceived integrity was significant and the interval excluded 0 (LLCI $=$ -0.1425 , ULCI $=-0.0151$ ). Therefore, the mediation effect of perceived integrity only exists in the context of value-related brand, and the hypothesis H1b was verified.

Then, the mediation effect of perceived benevolence was tested. The test result excluded 0 (LLCI $=-0.5258$, ULCI $=-0.0388)$, which means that the mediation effect of perceived benevolence is significant and the value of mediation effect is -0.2089 . Besides, after having controlled the mediating variable (i.e. perceived benevolence), the interaction between overcompensation information frame and the crisis type still obviously influenced increment of brand trust, and the interval excluded $0($ LLCI $=-1.5283$, ULCI $=-0.3069)$, which suggest that perceived benevolence is only partial mediation. Further analysis show that in the context of performance-related analysis, the mediation effect of perceived benevolence is significant and the interval (LLCI $=0.0324$, ULCI $=0.3976)$ excludes 0 ; while with the value-related crisis, the mediation effect of perceived benevolence isn't apparent, and the interval (LLCI $=-0.2039$, ULCI $=0.0689$ ) includes 0 . Therefore, the mediation effect of perceived benevolence only exists in the context of performance-related brand crisis. The hypothesis $\mathrm{H} 2 \mathrm{~b}$ was verified.

\section{Discussion}

This study utilized the relevant experiments to discuss the influences of overcompensation information frame upon the consumers' brand trust. The research results show that although the overcompensation can improve consumers' brand trust after the occurrence of certain crisis, these influences are moderated by the crisis type. Specifically, in the context of performance-related crisis, framing the overcompensation as the compensation for the victims' damages is most effective, during which the perceived benevolence has the mediation effects while the perceived integrity had no influences. With the value-related crisis, framing the overcompensation as punishing the misconducts of companies is the most effective; meanwhile, the perceived integrity has mediation effect, but the perceived benevolence has no influence.

Our research has made the following breakthroughs. Firstly, from the perspective of symbolic interaction, the overcompensation was discussed and analyzed, and demonstrate that the symbolic significance delivered by crisis response strategies are same important as strategies themselves. The Costly Signal Theory believes that individuals' some seemingly irrational and unworthy ac- 
tions deliver certain signals [36] and these signals are the important basis for inference and judgment. Overcompensation means that the compensation provided by companies to victims is more than the losses, which is not cost-effective and irrational for companies. Therefore, the symbolic significance delivered by the overcompensation is more important. Some scholars argue that the sum of compensation by means of overcompensation shall significantly influence the eventual effects of repair [3] [12]. However, some scholars believe that the compensation sum by means of overcompensation won't influence the repair effects [4] [5]. The differences in conclusions exist largely because of ignoring the symbolic significances carried by the overcompensation itself. The study of Okimoto (2008) [37] shows that the signals delivered by compensation could pose great significances upon people's behaviors than the material resources provided by the compensation. The studies of Dirks et al. (2011) [38] also demonstrate that only when the substantive repair measures by the companies deliver the signals of confession, consumers' trust could be improved. Gromet and Darley (2009) believe that overcompensation could be considered as the compensation for victims as well as the punishments posed upon the violators. Based on the studies of Gromet and Darley (2009), it's believed that the overcompensation can deliver the signal showing the integrity of companies, but also show off the companies' benevolence. It's consumers' perceived integrity and benevolence that determine consumers' trust upon a brand.

Secondly, based on Interaction Ritual Chain Theorys, the repairing of consumers' trust after the occurrence of crisis was discussed from the interaction perspective, which means that we consider company and consumer both in our research. The previous crisis-repairing researches are generally based on the attribution theory and image-restoration theory. The attribution theory starts from the perspective of companies, and believes that the starting point of crisis repairing is companies' attribution of responsibility in the crisis [1], while the image-restoration theory mainly focuses on the consumers' perspective and argues that the key to crisis repair is restoring the enterprise's images in the eye of consumers [39]. In recent years, the influences of interaction between consumers and companies upon the repairing of crisis have been lay much importance by scholars. The studies of Ran Xuanya and Wei Haiying (2015) show that in the process of repairing crisis, their emotional interaction with the consumers shall also influence the effects of crisis repair. The interaction should be conducted by two parties, and the successful interactive ceremonies need both parties to establish the mutual focus of attention, which means that the enterprise knowing the consumers' focus of attention shall not guarantee the successful interaction. Meanwhile, the repairing strategies should be chosen based on consumers' focus of attention. In the brand crisis, companies should repair crisis based on the crisis having occurred. Since the different types of crisis influence the consumers' focus of attention due to the different psychological distance with consumers, companies must choose the different overcompensation information frame based on consumers' focus of attention. 
Thirdly, it's believed that the key to the repairing of brand crisis is making up for victims' losses and reshaping consumers' belief that enterprise abides by the social standards. After the occurrence of brand crisis, what should be repaired by the enterprise has been an important item for scholars to research. Dirks (2009) [40] points out that crisis brings in the negative trust, negative mood and negative exchange to consumers. Therefore, the focuses of crisis repair should be on these three aspects. Consumers' trust should be improved by influencing consumers' attribution, negative moods reduced by reshaping the social relationships, positive exchange promoted by the structural arrangements. Ren (2009) [41] argues that crisis mainly influences the consumers' feeling of control and sense of identification. The true nature of brand crisis is consumers' losses caused by the enterprise's misconducts. Brand crisis influences the material benefits of consumers and their understandings about the social standards. When the consumers pay attention to the material losses caused by the crisis, the crisis shall affect their perceptions about achieving their own expected goals and controlling the results, reducing their own feelings of controlling, and causing the negative exchange. When consumers are deeply concerned with the companies' violation of social standards, they may suspect the companies' attitudes towards the social relationship under constraints by existing social standards; eventually, they shall doubt whether their identity as a social member is respected by the enterprise, their sense of identification is negatively influenced and negative moods appears. Furthermore, the eventual combination of the misconducts of companies and the material losses of consumers influences brand trust. Therefore, based on the studies of Dirks (2009) and Ren (2009), it's believed that the key to repairing of brand crisis is making up the victims' losses and reshaping consumers' belief that the companies obey the social standards. It's further pointed out that differentiating the goals of crisis repair reflects the difference in the focus of attention, and the focus of attention shall be different according to the varied crisis situations.

\section{Conclusions}

Based on the research conclusions of this paper, the inspirations for the management and practice in companies could be listed as follows. Firstly, before repairing the brand crisis, enterprise must clearly know the consumers' focus of attention. The process of repairing brand crisis is the interaction between enterprise and consumers. Getting to know customers' focus of attention is understanding their expectations, thus the repair measurements which meet consumers' expectations shall be provided. In the accident of benzene exceeding the standard induced by Jinhao Camellia Oil Company in 2010, the company compensated the consumers with 10 times of the standards, while the effects of overcompensation weren't as obvious as expected, which is largely because that although this accident brought great losses into consumers, the focus of attention of Jinhao Camellia Oil lies on their own misconducts and ignored paying attention to consumers so as to make consumers lose trust upon this brand. Se- 
condly, crisis type could be the anchor for enterprise to choose the appropriate strategies suited for the repair of crisis. After the occurrence of crisis, due to the lack of information, enterprise generally doesn't clearly how to deal with the brand crisis. However, determining the type of crisis shall provide the enterprise with an anchor for effective analysis. Consumers are the most important stakeholder of brand, as well as the primary target for the repairing of brand crisis. The different brand crises have varied relationships with the consumers. This differentiating shall impressively influence consumers' focus of attention which is the key to the determination of corresponding strategies taken by companies. Thus, confronted with brand crisis, the enterprise firstly should determine the type of crisis, and then infer consumers' focus of attention. Eventually, the appropriate crisis-repairing strategies can be chosen. Thirdly, overcompensation is an effective coping strategy, with its key being delivering the signals about companies' integrity and benevolence. The fact that overcompensation could be the effective crisis-repairing strategy not only because that it's able to provide more material supports, but also deliver the signals desired and expected by consumers. In the face of crisis, consumers' focus of attention generally determines what signals do they expect from the companies. When the consumers are deeply concerned with victims' losses, they are more likely to expect companies to show off their benevolence; when the consumers pay much attention to the misconducts of companies, they hope that companies should show respect to the social standards. Therefore, using overcompensation as a repairing measure, companies should put more efforts in the signals delivered by the overcompensation. Only with the appropriate signals delivered can the overcompensation become an effective coping strategy. Fourthly, punishment is also an effective strategy for repairing the brand crisis. The current studies regarding repairing the brand crisis mainly focus on repairing the economic relationship between consumers and brand, but ignore the repairing of social relationship. Located in the network of social relationship, companies are restrained by various social standards. Enterprise's misconducts inducing the brand crisis are the violation of social standards, as well as the key to inducing the consumers' negative emotions. Relevant studies suggest that the most effective of keeping the social standards is punishment. By means of punishment, violators shall clearly know the inappropriateness of their conducts so as to re-organize the social consensus and trigger the violators' wishes that social standards must be obeyed. Therefore, in the process of repairing crisis, companies should lay importance to the functions of punishment and deliver their wishes to obey the social standards by self-punishment.

This research has the following limitations. Firstly, although Interaction Ritual Chain Theory believes that the mutual focus of attention is the vital factor for the successful interaction, the successful interaction ritual needs the mating of emotional energy from both parties. This study only explores the influences of mutual focus of attention upon the effects of repairing brand crisis. The future study could explore the influences of matching of emotional energy from consumers and companies on the effects of repairing brand crisis. Secondly, al- 
though it's argued that determination of consumers' focus of attention is the anchor by which enterprise could choose the type of overcompensation information frame, in this study we only found out that the crisis type was able to influence consumers' focus of attention. In the future studies, we should discuss other factors which could influence consumers' focus of attention, such as the type of relationship between consumer and brand, the psychological distance between consumer and victim, social standards as well as the influences of media information frame so as to find more foundations for the decision making. Thirdly, this study was conducted with student samples. To ensure the effectiveness of research results, the sample size should be enlarged to make it more compelling.

\section{Acknowledgements}

This research was funded by the National Natural Science Foundation of China (71372169; 71302151; G020802), the Natural Science Foundation of Guangdong (2014A030311022); and Institute of Enterprise Development in Jinan University.

\section{References}

[1] Coombs, W.T. and Holladay, S.J. (2008) Comparing Apology to Equivalent Crisis Response Strategies: Clarifying Apology's Role and Value in Crisis Communication. Public Relations Review, 34, 252-257. https://doi.org/10.1016/j.pubrev.2008.04.001

[2] Desmet, P.T., De Cremer, D. and van Dijk, E. (2011) In Money We Trust? The Use of Financial Compensations to Repair Trust in the Aftermath of Distributive Harm. Organizational Behavior and Human Decision Processes, 114, 75-86. https://doi.org/10.1016/j.obhdp.2010.10.006

[3] Desmet, P.T., De Cremer, D. and van Dijk, E. (2010) On the Psychology of Financial Compensations to Restore Fairness Transgressions: When Intentions Determine Value. Journal of Business Ethics, 95, 105-115. https://doi.org/10.1007/s10551-011-0791-3

[4] Haesevoets, T., Van Hiel, A., Folmer, C.R. and De Cremer, D. (2014) What Money Can't Buy: The Psychology of Financial Overcompensation. Journal of Economic Psychology, 42, 83-95. https://doi.org/10.1016/j.joep.2014.02.001

[5] Haesevoets, T., Folmer, C.R., De Cremer, D. and Van Hiel, A. (2013) Money Isn't All That Matters: The Use of Financial Compensation and Apologies to Preserve Relationships in the Aftermath of Distributive Harm. Journal of Economic Psychology, 35, 95-107. https://doi.org/10.1016/j.joep.2013.02.003

[6] Peng, X. and Zhang, D. (2015) The Over-Compensation Effect under the Unintentional Transgression. Psychological Science, 38, 651-657

[7] Dutta, S. and Pullig, C. (2011) Effectiveness of Corporate Responses to Brand Crises: The Role of Crisis Type and Response Strategies. Journal of Business Research, 64, 1281-1287. https://doi.org/10.1016/j.jbusres.2011.01.013

[8] Gelbrich, K. and Roschk, H. (2011) Do Complainants Appreciate Overcompensation? A Meta-Analysis on the Effect of Simple Compensation vs. Overcompensation on Post-Complaint Satisfaction. Marketing Letters, 22, 31-47. https://doi.org/10.1007/s11002-010-9101-6

[9] McCollough, M.A., Berry, L.L. and Yadav, M.S. (2000) An Empirical Investigation of Customer Satisfaction after Service Failure and Recovery. Journal of Service Re- 
search, 3, 121-137. https://doi.org/10.1177/109467050032002

[10] Hess, R.L., Ganesan, S. and Klein, N.M. (2003) Service Failure and Recovery: The Impact of Relationship Factors on Customer Satisfaction. Journal of the Academy of Marketing Science, 31, 127-145. https://doi.org/10.1177/0092070302250898

[11] Noone, B.M. (2012) Overcompensating for Severe Service Failure: Perceived Fairness and Effect on Negative Word-of-Mouth Intent. Journal of Services Marketing, 26, 342-351. https://doi.org/10.1108/08876041211245254

[12] Gelbrich, K., Gäthke, J. and Grégoire, Y. (2015) How Much Compensation Should a Firm Offer for a Flawed Service? An Examination of the Nonlinear Effects of Compensation on Satisfaction. Journal of Service Research, 18, 107-123. https://doi.org/10.1177/1094670514543149

[13] Claeys, A., Cauberghe, V. and Leysen, J. (2013) Implications of Stealing Thunder for the Impact of Expressing Emotions in Organizational Crisis Communication. Journal of Applied Communication Research, 41, 293-308. https://doi.org/10.1080/00909882.2013.806991

[14] Van der Meer, T.G. (2014) Organizational Crisis-Denial Strategy: The Effect of Denial on Public Framing. Public Relations Review, 40, 537-539.

https://doi.org/10.1016/j.pubrev.2014.02.005

[15] Gromet, D.M. and Darley, J.M. (2009) Punishment and beyond: Achieving Justice through the Satisfaction of Multiple goals. Law \& Society Review, 43, 1-38. https://doi.org/10.1111/j.1540-5893.2009.00365.x

[16] Van Prooijen, J.W. (2010) Retributive versus Compensatory Justice: Observers' Preference for Punishing in Response to Criminal Offenses. European Journal of Social Psychology, 40, 72-85.

[17] Bastian, B., Jetten, J. and Fasoli, F. (2011) Cleansing the Soul by Hurting the Flesh: The Guilt-Reducing Effect of Pain. Psychological Science, 22, 334. https://doi.org/10.1177/0956797610397058

[18] Raihani, N.J. and Bshary, R. (2015) The Reputation of Punishers. Trends in Ecology \& Evolution, 30, 98-103. https://doi.org/10.1016/j.tree.2014.12.003

[19] Adams, G.S. and Mullen, E. (2013) Increased Voting for Candidates Who Compensate Victims Rather than Punish Offenders. Social Justice Research, 26, 168-192. https://doi.org/10.1007/s11211-013-0179-x

[20] Ran, Y. and Wei, H. (2015) The Mechanism of Brand Crisis Restoration: Based on Interaction Ritual Chain Theory. Journal of Marketing Science, 11, 18-33.

[21] Collins, L. (2009) Interaction Ritual Chain. Commercial Press, Beijing.

[22] Metiu, A. and Rothbard, N.P. (2013) Task Bubbles, Artifacts, Shared Emotion, and Mutual Focus of Attention: A Comparative Study of the Microprocesses of Group Engagement. Organization Science, 24, 455-475. https://doi.org/10.1287/orsc.1120.0738

[23] Cheung, C.K. and Li, J.C.M. (2011) Ritualized Interaction for the Advancement of Children's National Identification in Hong Kong. Journal of Applied Social Psychology, 41, 1486-1513. https://doi.org/10.1111/j.1559-1816.2011.00760.x

[24] Darley, J.M. and Pittman, T.S. (2003) The Psychology of Compensatory and Retributive Justice. Personality and Social Psychology Review, 7, 324-336. https://doi.org/10.1207/S15327957PSPR0704_05

[25] Tyler, T.R. and Blader, S.L. (2003) The Group Engagement Model: Procedural Justice, Social Identity, and Cooperative Behavior. Personality and social psychology review, 7, 349-361. https://doi.org/10.1207/S15327957PSPR0704_07

[26] McFall, L. (1987) Integrity. Ethics, 98, 5-20. https://doi.org/10.1086/292912 
[27] Loewenstein, G. and Small, D.A. (2007) The Scarecrow and the Tin Man: The Vicissitudes of Human Sympathy and Caring. Review of General Psychology, 11, 112-126. https://doi.org/10.1037/1089-2680.11.2.112

[28] Leliveld, M.C., Dijk, E. and Beest, I. (2012) Punishing and Compensating Others at Your Own Expense: The Role of Empathic Concern on Reactions to Distributive Injustice. European Journal of Social Psychology, 42, 135-140. https://doi.org/10.1002/ejsp.872

[29] Foa, E.B. and Foa, U.G. (2012) Resource Theory of Social Exchange. Handbook of Social Resource Theory, Springer, New York.

[30] Livnat, Y. (2003) Benevolence and Justice. The Journal of Value Inquiry, 37, 507515. https://doi.org/10.1023/B:INQU.0000019054.47424.a1

[31] Xie, Y. and Peng, S. (2009) How to Repair Customer Trust after Negative Publicity: The Roles of Competence, Integrity, Benevolence, and Forgiveness. Psychology \& Marketing, 26, 572-589. https://doi.org/10.1002/mar.20289

[32] Kim, P.H., Ferrin, D.L., Cooper, C.D. and Dirks, K.T. (2004) Removing the Shadow of Suspicion: The Effects of Apology versus Denial for Repairing Competence-Versus integrity-Based Trust Violations. Journal of Applied Psychology, 89, 104. https://doi.org/10.1037/0021-9010.89.1.104

[33] Zhao, X., Lynch, J.G. and Chen, Q. (2010) Reconsidering Baron and Kenny: Myths and Truths about Mediation Analysis. Social Science Electronic Publishing, 37, 197-206. https://doi.org/10.1086/651257

[34] Preacher, K.J. and Hayes, A.F. (2004) SPSS and SAS Procedures for Estimating Indirect Effects in Simple Mediation Models. Behavior Research Methods Instruments, \& Computers, 36, 717-731. https://doi.org/10.3758/BF03206553

[35] Hayes, A.F. (2013) Introduction to Mediation, Moderation, and Conditional Process Analysis: A Regression-Based Approach. Journal of Educational Measurement, 51, 335-337.

[36] Soler, M. (2012) Costly Signaling, Ritual and Cooperation: Evidence from Candomblé, an Afro-Brazilian Religion. Evolution and Human Behavior, 33, 346-356. https://doi.org/10.1016/j.evolhumbehav.2011.11.004

[37] Okimoto, T.G. (2008) Outcomes as Affirmation of Membership Value: Material Compensation as an Administrative Response to Procedural Injustice. Journal of Experimental Social Psychology, 44, 1270-1282. https://doi.org/10.1016/j.jesp.2008.04.009

[38] Dirks, K.T., Kim, P.H., Ferrin, D.L. and Cooper, C.D. (2011) Understanding the Effects of Substantive Responses on Trust Following a Transgression. Organizational Behavior and Human Decision Processes, 114, 87-103. https://doi.org/10.1016/j.obhdp.2010.10.003

[39] Benoit, W.L. (1997) Image Repair Discourse and Crisis Communication. Public Relations Review, 23, 177-186. https://doi.org/10.1016/S0363-8111(97)90023-0

[40] Dirks, K.T., Lewicki, R.J. and Zaheer, A. (2009) Reparing Relationships within and between Organizations: Building a Conceptual Foundation. Academy of Management Review, 34, 68-84. https://doi.org/10.5465/AMR.2009.35713285

[41] Ren, H. and Gray, B. (2009) Repairing Relationship Conflict: How Violation Types and Culture Influence the Effectiveness of Restoration Rituals. Academy of Management Review, 34, 105-126. https://doi.org/10.5465/AMR.2009.35713307 
Submit or recommend next manuscript to SCIRP and we will provide best service for you:

Accepting pre-submission inquiries through Email, Facebook, LinkedIn, Twitter, etc. A wide selection of journals (inclusive of 9 subjects, more than 200 journals)

Providing 24-hour high-quality service

User-friendly online submission system

Fair and swift peer-review system

Efficient typesetting and proofreading procedure

Display of the result of downloads and visits, as well as the number of cited articles Maximum dissemination of your research work

Submit your manuscript at: http://papersubmission.scirp.org/

Or contact jssm@scirp.org 